\title{
Incidence of Lingual Nerve Paresthesia after Surgical Removal of Mandibular Third Molar Surgery
}

\author{
Research Article
}

P Aditya Reddy ${ }^{1}$, Abdul Wahab PU² ${ }^{2}$, Jagadish $V^{3}$

${ }^{1}$ Department of Oral \& Maxillofacial Surgery, Saveetha Dental College and Hospitals, Saveetha Institute of Medical and Technical Sciences, Saveetha University, Chennai, India.

${ }^{2}$ Professor, Department of Oral \& Maxillofacial Surgery, Saveetha Dental College and Hospitals, Saveetha Institute of Medical and Technical Sciences, Saveetha University, Chennai, India.

${ }^{3}$ Senior Lecturer, Department of Oral \& Maxillofacial Surgery, Dental College and Hospitals, Saveetha Dental College and Hospitals, Saveetha Institute of Medical and Technical Sciences, Saveetha University, Chennai, India.

\section{Abstract}

\begin{abstract}
Aim: To determine the incidence of lingual nerve injury during surgical removal of mandibular third molar. Study Design: Retrospective study study Place and Duration:Saveetha dental college and hospital for 10months.

Materials and Methods: A retrospective audit was carried out and incidence of paresthesia was documented.

Results: A total of 720 patients underwent surgical removal lower third molar,only 420 patients came for review. Out of these three patients reported Lingual nerve paraesthesia that was temporary. There was no patient reporting with temporary and permanent inferior alveolar nerve paraesthesia.

Conclusion: It was concluded that the factors leading to temporary or permanent paraesthesia is actually a difficulty of extraction. Other parameters like operator's seniority, age and medical condition of the patient, gender, level of impaction, type of flap and the tooth side in relation to the handedness of the operator had minimal effect on the outcome.
\end{abstract}

Keywords: Lingual Nerve Injury; Sensory Impairment; Third Molar Extraction; Inferior Alveolar Nerve Injury.

\section{Introduction}

Dentistry comprises practices related to oral cavity. Oral diseases are a major problem among general population and there are various procedures carried out to prevent and treat them. Oral health have a direct impact on general health patterns as it helps to talk ,eat and feel confident [1]. Third molar surgery is one of the most common procedures performed by oral surgeons/oral and maxillofacial surgeons. Surgical alterations in the position of the bony facial skeleton will inevitably affect the soft tissues [2]. There is a documented complication of inferior alveolar nerve and lingual nerve damage which leads to paraesthesia of the lower lip, chin and tongue. Extraction of the mandibular third molars is one of the most frequently performed procedures in oral and maxillofacial surgery. Despite improvement in the preoperative assessment of impacted lower wisdom teeth and techniques of removal; Inferior alveolar and lingual nerve damage remains a significant factor during 3rd molar surgery which has serious medical and legal implications. In previous studies, the prevalence of damage to the lingual nerve (LN) varied from almost $0 \%$ to $23 \%[3,4]$. This lesion may involve temporary or permanent lingual sensory disturbances. The incidence of temporary deficit is between $0-23 \%$ and permanent $0-8 \%$, compared with temporary (0.4 to $8.4 \%$ ) and permanent $(<1 \%)$ lesion of the inferior alveolar nerve $[5,6]$. Literature quotes various reasons for post-operative paraesthesia of the lip, chin and tongue following mandibular third molar extractions varying from inadequate protection and inadequate assessment to seniority of the operator $[6,7]$.

The present study was conducted to determine the incidence of lingual nerve injury and to correlate the various factors associated with lingual nerve paresthesia during surgery.

\section{Materials and Methods}

A retrospective study on incidence of lingual nerve paresthesia

*Corresponding Author:

Dr. Abdul Wahab P U,

Professor, Department of Oral \& Maxillofacial Surgery, Saveetha Dental College and Hospitals, Saveetha Institute of Medical and Technical Sciences, Saveetha University, Chennai, India.

E-mail: 151804003.sdc@saveetha.com

Received: October 07, 2020

Accepted: November 22, 2020

Published: November 25, 2020

Citation: P Aditya Reddy, Abdul Wahab PU, Jagadish V. Incidence of Lingual Nerve Paresthesia after Surgical Removal of Mandibular Third Molar Surgery. Int J Dentistry Oral Sci. 2020;7(11):1072-1075. doi: http://dx.doi.org/10.19070/2377-8075-20000212

Copyright: Abdul Wahab P U ${ }^{\circ} 2020$. This is an open-access article distributed under the terms of the Creative Commons Attribution License, which permits unrestricted use, distribution and reproduction in any medium, provided the original author and source are credited. 
who came to saveetha dental college referred to the department of oral and maxillofacial surgery. The data were collected for patients who underwent surgical removal of lower third molar from june-2019 to march-2020. The data collected were reviewed and analysed the data of 86000 patients. Patient review notes were taken and complaints were noted. All the data was collected and recorded in EXCEL and transferred to spss(2.0).

Inclusive Criteria: Patient who underwent surgical removal of lower third molar surgery.

Excluding Criteria: All other surgical removal of teeth except lower third molar was excluded from the study. All incomplete data was excluded from the study.

\section{Results and Discussion}

Total of 720 surgical removal of impacted surgeries reported out of which 420 cases came for review, 368 cases underwent surgical removal of mandibular third molar. 221 male $(60.16 \%)$ and $147(39.85 \%)$ ) were females (figure: 1). The mean age was 29.3 years minimum of 24 years and maximum of age 69 years Out of 368, 201 are left mandibular third molars (38 ISO 3950 tooth numbering system)and 165 were lower right third molars (48 ISO 3950 tooth numbering system )(figure:2). Out of 368 patients the lingual nerve paresthesia was present in $3(0.84 \%)$ patients and the rest $365(99.16 \%)$ patients were not having any signs of lingual nerve paresthesia (figure:3). Comparison between association of teeth involved and presence of lingual nerve paresthesia, it was found that $0.82 \%$ of lingual nerve paresthesia was present after

Figure 1. The following bar chart represents gender of the patients. Color purple represents males (60.16\%) and color yellow represents females $(39.84 \%)$. From the above pie chart it is evident that surgical removal of mandibular third molars are carried out more in males when compared to females.

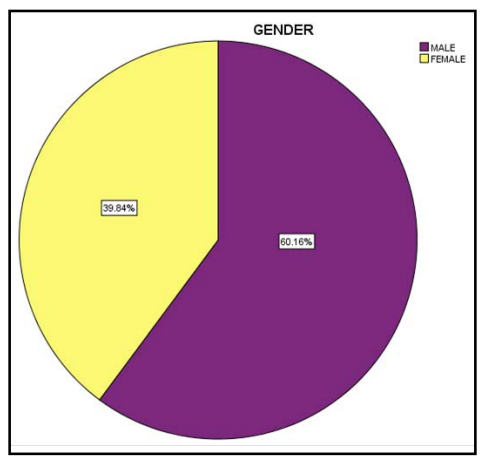

Figure 2. The following bar chart represents the tooth . Color orange represents surgical removal of $38(53.70 \%)$ and color red represents surgical removal of $48(46.30 \%)$. The above pie chart denotes that surgical removal of 38 teeth is more when compared to 48 .

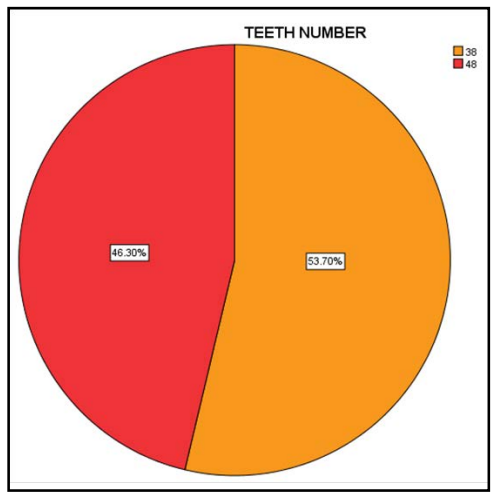

Figure 3. The following pie chart represents lingual nerve paresthesia. Color blue represents absence of lingual nerve paresthesia (99.16\%) and color green represents presence of lingual nerve paresthesia. From the above pie chart it is evident that the presence of lingual nerve paresthesia is relatively low.

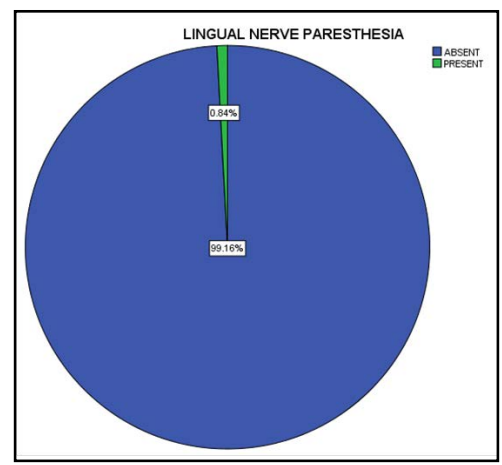


extraction of impacted 38. Pearson chi- square value - 5.674, df value is $1, \mathrm{p}$ value $-0.17(<0.05)$ statistically not significant (figure:4). Therefore there is no correlation between teeth involved and the lingual nerve paresthesia. Association between gender and lingual nerve paresthesia was carried out, it was found that lingual nerve damage is more in male $(0.54 \%)$ compared to females $(0.27 \%)$. Pearson chi- square value -0.57 , df value is 1 , $\mathrm{p}$ value $-0.811(>0.05)$ statistically not significant (figure 5$)$. Association between age of the patient and lingual nerve paresthesia was done, it was found that lingual nerve paresthesia is seen more in the age group of $41-50(0.54 \%)$ years and $31-40(0.27 \%)$ years (figure 6). Pearson chi-square test was carried out, its value -18.707 , df value is $1, \mathrm{p}$ value $-0.001(<0.05)$, therefore it was statistically significant.
This figure was close to the study conducted by Lata (2011) in which he reported $6.6 \%$ of lingual nerve paresthesia [8]. Incidence of inferior alveolar nerve paresthesia was reported as $0.0 \%$ in the present study. Rood (1983) reported an initial incidence of $6.6 \%$ lingual nerve injury, Blackburn and Bramley $11 \%$ and VonArx and Simpson (1997) reported 22\% [9]. Another study reported $5 \%$ cases of lingual nerve injury that was not permanent and all the patients with lingual nerve damage had recovered within three months [10]. F.A. Carmichale in 1992 recorded 1339 impacted third molar removal and their change in sensation by direct questioning at 6 to 24 hours and 7 to 10 days and by the incidence of lingual nerve damage was found to be $15 \%$ of operated site at 16 to 24 hours, $10.7 \%$ at 7 to 10 days and $0.6 \%$

Figure 4. The above bar graph represents the association between the teeth involved and the presence of lingual nerve paresthesia. $X$ axis represents the presence of lingual nerve paresthesia and the $\mathrm{Y}$ axis represents the number of patients. Pearson chi- square value 2.697 , $\mathrm{df}$ value is 1 , $\mathrm{p}$ value -0.101 $(>0.05)$ statistically not significant. Lingual nerve paresthesia is more common in 38 than in 48 , but there is no significant association.

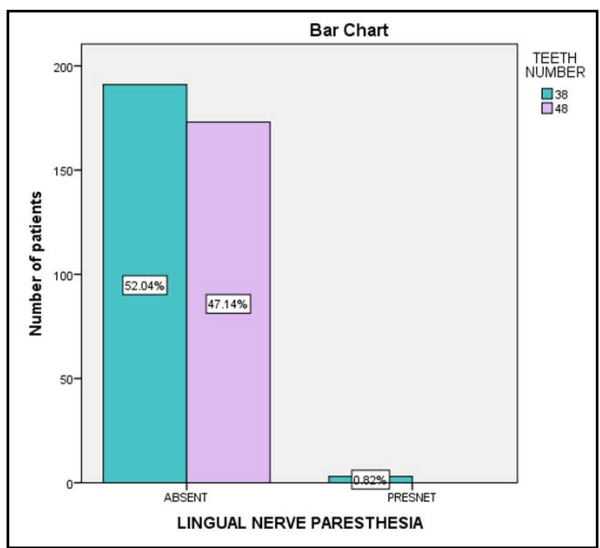

Figure 5. The above bar graph represents the association between lingual nerve paresthesia and gender. $X$ axis represents presence of lingual nerve paresthesia and $\mathrm{Y}$ axis represents number of patients. Lingual nerve damage is relatively more in males than females. Pearson chi- square value-0.57, df-1 value-0.811(>0.05)statistically non significant.

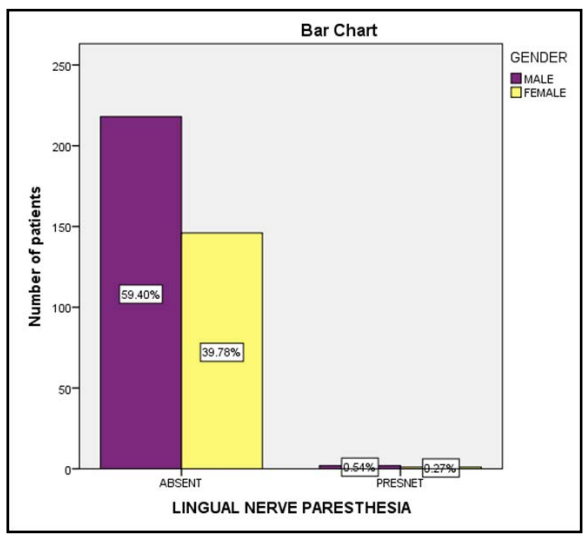

Figure 6. The above bar graph represents the association between lingual nerve paresthesia and age of the patient. $\mathrm{X}$ axis represents presence of lingual nerve paresthesia and $\mathrm{Y}$ axis represents number of patients. Pearson chi- square value $-18.707, \mathrm{df}$ value is $1, \mathrm{p}$ value $-0.001(<0.05)$ statistically significant.

From the above bar graph it is evident that lingual nerve damage is more seen in the age group of $41-50$ years of age with $0.54 \%$ and $0.27 \%$ in the age group of 31-40 years.

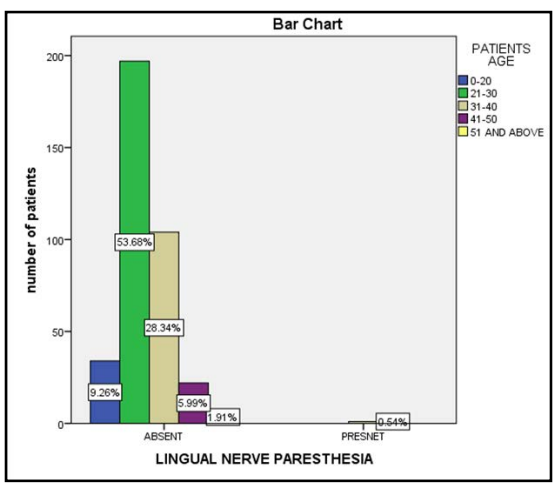


after 1 year [6]. Saurabh suggested that Lingual nerve damage was found to be more in the age group 24-40 years while Bruce 1980 suggested that incidence of lingual nerve damage increases with age [11]. The less the experience of the operator, the higher the chances of lingual nerve damage because of difficult surgical procedure. The lingual nerve damage may occur due to fully bony impacted lower third molar, extensive flap retraction for a longer time. Similarly extensive bone cutting may lead to the nerve damage and excessive bleeding. Tranexamic acid has been shown to be an effective method of reducing blood loss during surgical procedures $[12,13]$. Also Most patients are not aware of the complications of surgery [14]. In some studies no statistical difference was found among the different operators and the frequency of impaired lingual sensation. The frequency of lingual nerve damage was found to be less when operated by Professors and Associate Professors (3.6\%) [15]. The present study also showed that lingual nerve damage was more when operated by postgraduate trainees as compared to consultants. It is important for dental students to improve their knowledge to enable diagnosis and management of patients to have a more positive attitude toward these patients [16-18]. A case of permanent paresthesia of lingual nerve was also operated by postgraduate trainees. Elevation of lingual flap and protection of the nerve with an appropriate retractor is an important part of the surgery. However, we have to keep in notice that lingual flaps are raised in more complex cases thus, there is an increased risk of temporary or permanent paresthesia [19, 20]. Also most of the human pathogens have been isolated from oral secretions [21]. Several factors may influence the perception of sensation as it is a complex process. dental factors needs to be considered more often as a possible diagnosis also [22-25]. Lingual flaps when can be avoided shall be and when raised then appropriate protection shall be given to the nerve. As far as lingual flap elevation is concerned, a detailed study is required to find out a better technique for its elevation.

\section{Conclusion}

From our present study it is clear that, male patients are affected more by lingual nerve damage than female patients during surgical extraction of impacted molars which is more particularly seen after extraction of lower left impacted third molar and most commonly in third and fourth decade of life. Lingual nerve paresthesia after surgical removal of third molar is relatively low which is dependent on various factors. Proper diagnostic aids, treatment planning and surgical procedure will aid in better outcomes. Furthermore study with large sample size and single operator is needed in assessing the exact outcome.

\section{Acknowledgements}

The authors would like to acknowledge the help and support rendered by the department of oral and maxillofacial surgery, Medical records department and information technology of Saveetha Dental College and Hospitals for their constant assistance with the research.

\section{References}

[1]. Patturaja K, Pradeep D. Awareness of Basic Dental Procedure among General Population. Res J Pharm Technol. 2016;9(9):1349-51.

[2]. Vijayakumar Jain S, Muthusekhar MR, Baig MF, Senthilnathan P, Logana- than S, Abdul Wahab PU, et al. Evaluation of Three-Dimensional Changes in Pharyngeal Airway Following Isolated Lefort One Osteotomy for the Correction of Vertical Maxillary Excess: A Prospective Study. J Maxillofac Oral Surg. 2019 Mar;18(1):139-146.Pubmed PMID: 30728705.

[3]. Brodrick GC. The History of England, from Addington's Administration to the Close of William IV's Reign (1801-1837) (Classic Reprint). Forgotten Books; 2016. $512 \mathrm{p}$.

[4]. Shepherd JP. Lingual nerve retraction increases the risk of temporary lingual nerve damage during mandibular third molar surgery. Evid Based Dent. 2006 Jun; 7(2):47.

[5]. Gülicher D, Gerlach KL. Sensory impairment of the lingual and inferior alveolar nerves following removal of impacted mandibular third molars. Int J Oral Maxillofac Surg. 2001 Aug;30(4):306-12.Pubmed PMID: 11518353.

[6]. Carmichael FA, McGowan DA. Incidence of nerve damage following third molar removal: a West of Scotland Oral Surgery Research Group study. Br J Oral Maxillofac Surg. 1992 Apr;30(2):78-82.Pubmed PMID: 1567807.

[7]. Hillerup $S$. Iatrogenic injury to the inferior alveolar nerve: etiology, signs and symptoms, and observations on recovery. Int. J. Oral Maxillofac. Surg. 2008 Aug 1;37(8):704-9.

[8]. Lata J, Tiwari AK. Incidence of lingual nerve paraesthesia following mandibular third molar surgery. Natl J Maxillofac Surg. 2011 Jul;2(2):137-40. Pubmed PMID: 22639500.

[9]. Website [Internet]. [cited 2020 Jun 10]. Available from: Graff-Radford SB, Evans RW. Lingual nerve injury: incidence.

[10]. Broderick D, Rogers S, Ryan D, Stassen LF. Lingual nerve strain during lingual flap reflection \& nerve protection: a cadaver study. Br J Oral Maxillofac Surg. 2013 Sep 1;51(6):e106.

[11]. Lyons CJ, Bruce RA, Frederickson GC, Small GS. Age of patients and morbidity associated with mandibular third molar surgery. J Am Dent Assoc. 1980 Aug 1;101(2):240-5.

[12]. Christabel A, Anantanarayanan P, Subash P, Soh CL, Ramanathan M, Muthusekhar MR, et al. Comparison of pterygomaxillarydysjunction with tuberosity separation in isolated Le Fort I osteotomies: a prospective, multi-centre, triple-blind, randomized controlled trial. Int J Oral Maxillofac Surg. 2016 Feb;45(2):180-5.Pubmed PMID: 26338075.

[13]. Packiri S, Gurunathan D, Selvarasu K. Management of paediatric oral ranula: a systematic review. J. Clin. Diagnostic Res. 2017 Sep;11(9):ZE06.

[14]. Jesudasan JS, Wahab PU, Sekhar MR. Effectiveness of $0.2 \%$ chlorhexidine gel and a eugenol-based paste on postoperative alveolar osteitis in patients having third molars extracted: a randomised controlled clinical trial. $\mathrm{Br} \mathrm{J}$ Oral Maxillofac Surg. 2015 Nov;53(9):826-30.Pubmed PMID: 26188932.

[15]. Grames M, Leverentz C. Attitudes Toward Persons with Disabilities: A Comparison of Chinese and American Students [Internet]. PsycEXTRA Dataset. 2010.

[16]. Abhinav RP, Selvarasu K, Maheswari GU, Taltia AA. The Patterns and Etiology of Maxillofacial Trauma in South India. Ann Maxillofac Surg. 2019 Jan-Jun;9(1):114-117.Pubmed PMID: 31293938.

[17]. Kumar S, Snena S. Knowledge and awareness regarding antibiotic prophylaxis for infective endocarditis among undergraduate dental students. Asian J Pharm Clin Res. 2016;9:154-9.

[18]. RAHMAN R, MP SK. KNOWLEDGE, ATTITUDE, AND AWARENESS OF DENTAL UNDERGRADUATE STUDENTS REGARDING HUMAN IMMUNODEFICIENCY VIRUS/ACQUIRED IMMUNODEFICIENCY SYNDROME PATIENTS. Asian J Pharm Clin Res. 2017;10(5):175-80.

[19]. Marimuthu M, Andiappan M, Wahab A, Muthusekhar MR, Balakrishnan A, Shanmugam S. Canonical Wnt pathway gene expression and their clinical correlation in oral squamous cell carcinoma. Indian J Dent Res. 2018 MayJun;29(3):291-297.Pubmed PMID: 29900911.

[20]. Patil SB, Durairaj D, Suresh Kumar G, Karthikeyan D, Pradeep D. Comparison of Extended Nasolabial Flap VersusBuccal Fat Pad Graft in the Surgical Management of Oral Submucous Fibrosis: A Prospective Pilot Study. J Maxillofac Oral Surg. 2017 Sep;16(3):312-321.Pubmed PMID: 28717289.

[21]. Kumar S, Rahman RE. Knowledge, awareness, and practices regarding biomedical waste management among undergraduate dental students. Asian J Pharm Clin Res. 2017;10:341.

[22]. Kumar S. Relationship between dental anxiety and pain experience during dental extractions. Asian J Pharm Clin Res. 2017;10(3):458-61.

[23]. Rao TD, Kumar MP. Analgesic Efficacy of ParacetamolVs Ketorolac after Dental Extractions. Res J Pharm Technol. 2018;11(8):3375-9.

[24]. Kumar S. THE EMERGING ROLE OF BOTULINUM TOXIN IN THE TREATMENT OF OROFACIAL DISORDERS: LITERATURE UPDATE [Internet]. Vol. 10, Asian Journal of Pharmaceutical and Clinical Research. 2017. p. 21.

[25]. Sweta VR, Abhinav RP, Ramesh A. Role of Virtual Reality in Pain Perception of Patients Following the Administration of Local Anesthesia. Ann Maxillofac Surg. 2019 Jan-Jun;9(1):110-113.Pubmed PMID: 31293937. 